\title{
What is beyond Salmonella gastroenteritis? A case of acute pancreatitis complicating Salmonella infection in a child: a case report and literature review
}

\author{
Salwa Al Kaabi ${ }^{1 *}$, Aysha Al Kaabi ${ }^{1}$ and Hasa Al Nuaimi ${ }^{2}$
}

\begin{abstract}
Background: Salmonella infection presents itself in a wide variety of ways, ranging from mild self-limited illness to severe systemic disease with multiorgan involvement. Acute pancreatitis (AP) is a very rare complication that is associated with Salmonella infection, especially among the pediatric population.

Case presentation: A five-year-old boy presented with a two-day fever and experienced vomiting, diarrhea, and abdominal pain. The boy was admitted as a case of acute gastroenteritis, and Salmonella was found in his stool culture. The severity of his abdominal pain during his hospital stay indicated the possibility of AP. A clinical examination and blood workup were performed and showed significant elevation in amylase and lipase, which confirmed the diagnosis of AP.
\end{abstract}

Conclusion: Although abdominal pain is a common presentation of Salmonella infection, the possibility of AP must be considered when the pain is severe and the characteristics of the pain are suggestive of AP. Herein, we report a case of AP complicating Salmonella infection in an immunocompetent child.

Keywords: Salmonella gastroenteritis, Pancreatitis, Amylase, Lipase

\section{Background}

Acute pancreatitis (AP) is the most common pancreatic disorder in children, and its incidence is increasing worldwide [1]. Recent studies have estimated the incidence of AP in children to be approximately $1 / 10,000$ children per year, an incidence approaching that in adult patients [2] [3].

At present, there are no evidence-based diagnostic guidelines for the diagnosis of AP in children. The expert definition of pediatric AP from the International Study Group of Pediatric Pancreatitis (INSPPIRE) is

\footnotetext{
* Correspondence: salsaeed@seha.ae

'Pediatrics Department, General Pediatrics Division, Tawam Hospital, P.O. Box 15258, Al Ain, UAE

Full list of author information is available at the end of the article
}

modeled after the Atlanta classification in adult patients [4]. As per INSPPIRE criteria, a diagnosis of acute pancreatitis requires at least two of the following [5] [6]:

1. Abdominal pain compatible with acute pancreatitis

2. Serum amylase and/or lipase $\geq 3$ times upper limits of normal

3. Imaging findings consistent with acute pancreatitis

In children, blunt abdominal injuries, multisystem disease, biliary stones or microlithiasis, and drug toxicity are the most common contributing factors of AP [1]. The severity of AP is highly variable, with most patients recovering spontaneously with supportive treatment

C C The Author(s). 2021 Open Access This article is licensed under a Creative Commons Attribution 4.0 International License, which permits use, sharing, adaptation, distribution and reproduction in any medium or format, as long as you give appropriate credit to the original author(s) and the source, provide a link to the Creative Commons licence, and indicate if changes were made. The images or other third party material in this article are included in the article's Creative Commons licence, unless indicated otherwise in a credit line to the material. If material is not included in the article's Creative Commons licence and your intended use is not permitted by statutory regulation or exceeds the permitted use, you will need to obtain permission directly from the copyright holder. To view a copy of this licence, visit http://creativecommons.org/licenses/by/4.0/. The Creative Commons Public Domain Dedication waiver (http://creativecommons.org/publicdomain/zero/1.0/) applies to the data made available in this article, unless otherwise stated in a credit line to the data. 
only. Further, it is not uncommon for AP to lead to death if left untreated [4].

AP complicating Salmonella gastroenteritis is a rare complication among the pediatric population. This complication has been reported in adult patients with typhoid fever and nontyphoid Salmonella infection, but there are few reported cases in the pediatric population [7]. Herein, we report a case of AP complicating Salmonella gastroenteritis infection in an immunocompetent child.

\section{Case presentation}

A five-year-old boy, previously healthy, presented with a two-day history of fever and experienced vomiting, diarrhea, and abdominal pain. Although his fever was high, it was not associated with chills or rigors. Vomiting was frequent but not projectile, nor was the vomit bilious or mixed with blood. The diarrheal stool was watery in nature and mixed with mucus, but no blood was detected. The abdominal pain was severe and colicky in nature, located in the epigastric area with no radiation. The pain was relieved by passing stool, with no other painrelieving factors, including pain medications. Further, the pain was aggravated by food intake. No abdominal distension, no history of drug ingestion and no recent travel.

A physical examination on admission revealed a highly febrile child with a fever reaching $40^{\circ} \mathrm{C}$, tachycardia and otherwise normal vital signs. He also showed signs that indicated moderate dehydration. His physical examination, including an abdominal examination was unremarkable.

Blood investigations revealed normal complete blood count, with normal renal function and electrolytes. Blood and urine cultures were also normal. He had low bicarbonate level of $14 \mathrm{mmol} / \mathrm{L}$ (Normal Range: 22-26 $\mathrm{mmol} / \mathrm{L}$ ) and the rapid antigen detection test was positive for Group A streptococcal (GAS) infection. Table 1.

The patient was admitted with the suspicion of GAS infection (tonsillitis), and his abdominal pain was attributed to mesenteric adenitis, which is usually associated with GAS infection. The patient was started on intravenous (IV) hydration and penicillin G sodium. Further, the patient did not have a sore throat at that stage, and his clinical examination did not reveal any sign of GAS tonsillitis.

On the second and third days of his hospital stay, the patient continued to have a high-grade fever, abdominal pain, and diarrhea, but his pain was controlled with IV paracetamol.

On the fourth day of his hospital stay, the patient's abdominal pain worsened, and he complained of severe abdominal pain localized to the epigastric area. This pain was aggravated by food intake and relieved by IV paracetamol and nonsteroidal anti-inflammatory drugs. He continuously spiked a high-grade fever with worsening diarrhea that was associated with tenesmus.

The examination revealed that the child was highly febrile (temperature above $39^{\circ} \mathrm{C}$ ) and tachycardic with normal blood pressure. His abdominal examination revealed severe tenderness throughout the abdomen, but a detailed examination could not be performed, as the patient was in severe pain and refused to be examined. The possibilities of an intra-abdominal abscess, acute pancreatitis, surgical abdomen, and bacterial colitis were considered at that stage, and further investigations were conducted to identify any serious pathology. His WBC count remained normal for his age, with a count of $6000 / \mathrm{ml}(4500-13,500 / \mathrm{ml})$ that mainly showed neutrophil predominance $(62 \%)$ and immature cells $(4 \%)$. His hemoglobin dropped to $9.9 \mathrm{~g} / \mathrm{dL}(11.5 \mathrm{~g} / \mathrm{dL})$, and his platelet count remained normal. His $\mathrm{C}$-reactive protein (CRP) concentration was checked and was significantly elevated, with a value of $120.6 \mathrm{mg} / \mathrm{L}$ (Normal Range: 0$5 \mathrm{mg} / \mathrm{L}$ ) [8]. His renal and liver function parameters remained normal, and his bicarbonate level improved from $14 \mathrm{mmol} / \mathrm{L}$ to $19 \mathrm{mmol} / \mathrm{L}(22-26 \mathrm{mmol} / \mathrm{L})$. Pancreatic enzymes were elevated, with an amylase level of 101 units/L (Normal Range: 25-101 units/L) and a lipase level of $169 \mathrm{IU} / \mathrm{L}$ (Normal Range: 3-32 IU/L) [8]. An abdominal ultrasound (US) was performed to rule out intra-abdominal pathology and showed a small amount of free fluid in the lower abdomen (mainly in the left lower quadrant), with an estimated volume of approximately $20 \mathrm{~mL}$ and few prominent mesenteric lymph nodes (Fig. 1). The pancreas was visualized and appeared normal. Mild pelviectasis was also detected, with a diameter of $1 \mathrm{~cm}$ and a mildly prominent proximal left ureter.

At this stage, the patient was treated as a case of AP following the standard protocol of nil per os and IV analgesia to control his pain. The possibilities of an intraabdominal abscess and surgical abdomen could not be ruled out; therefore, the antibiotic was upgraded from penicillin to piperacillin-tazobactam to provide wider coverage for gram-negative enteric organisms and anaerobes. A surgical consultation was obtained, and the surgical team chose supportive management.

On the sixth day of his hospital stay, the patient still experienced severe abdominal pain; therefore, the abdominal US was repeated, together with an abdominal $\mathrm{X}$-ray. He was scheduled for computed tomography of the abdomen on fourth day of admission to rule out any serious pathology that could have been missed by the US, but the family refused the procedure. Abdominal US showed a fluid pocket of $11 \mathrm{cc}$ in the left iliac fossa (which is an improving compared to the previous scan) and another $8 \mathrm{cc}$ pocket of fluid on the right side, with small para-aortic and mesenteric lymph nodes that were 


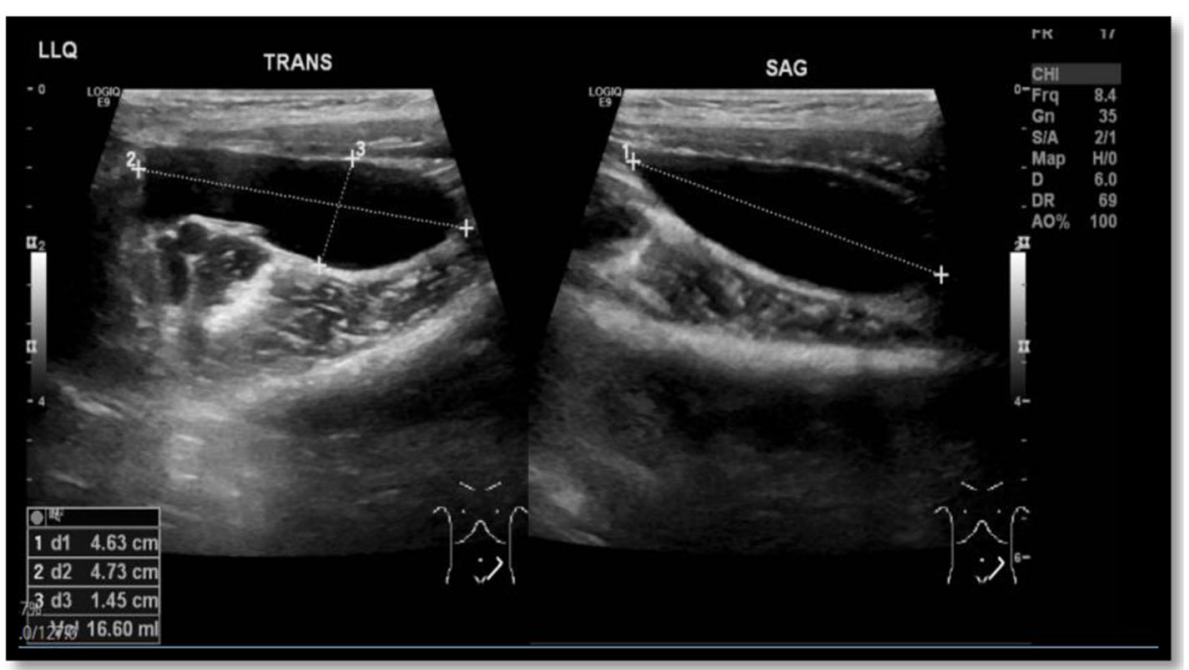

Fig. 1 Abdominal US showing a small amount of free fluid $(20 \mathrm{ml})$ in the lower abdomen (mainly in the left lower quadrant)

most likely reactive as per the radiologist report. The abdominal X-ray showed gas distension of the transverse colon, with no other abnormalities (Fig. 2). Additionally, pancreatic enzyme analysis was repeated at this stage to check the trend, and upward trends in both enzymes were indicated (amylase increased from 101 units/L to 131 units/L (25-101 units/L) and lipase increased from $169 \mathrm{IU} / \mathrm{L}$ to $293 \mathrm{IU} / \mathrm{L}(3-32 \mathrm{IU} / \mathrm{L}))$. A test of CRP levels was also repeated and showed an upward trend, from $120 \mathrm{mg} / \mathrm{L}$ to $123 \mathrm{mg} / \mathrm{L}(0-5 \mathrm{mg} / \mathrm{L})$. Blood and urine cultures were negative at this stage.

The patient's condition continued to be managed as a case of pancreatitis. The gastroenterology team's input was requested at this stage, and they recommended continuing supportive management, monitoring the trend in amylase/lipase on a daily basis, and considering starting a free fluid followed by a fat-free diet. The patient was started on IV morphine for better pain management and omeprazole to avoid stress-induced ulcers.

On the seventh day of his hospital stay, the patient's abdominal pain and diarrhea started to improve, and his stool culture was reported to be positive for Salmonella group B. Repeated amylase analyses initially showed an upward trend but then trended down (day 15 of admission), and repeated lipase analyses showed a downward trend (day 11 of admission), correlating with clinical improvement (Fig. 3). Repeated inflammatory marker (CRP) analyses showed a downward trend, from $123 \mathrm{mg} /$ $\mathrm{L}(0-5 \mathrm{mg} / \mathrm{L})$ (on day 6 of admission) to $13 \mathrm{mg} / \mathrm{L}(0-5$ $\mathrm{mg} / \mathrm{L}$ ) (on day 11 of admission).

Thereafter, the patient continued to show gradual improvement in his abdominal pain, fever, and diarrhea, and he was gradually started on a regular diet. His fever subsided on day 11 of the hospital stay, as did his abdominal pain and diarrhea. Later, the patient was discharged home with full recovery and with a close followup with gastroenterology, infectious disease, and general pediatric teams. The patient presented to the outpatient clinic for follow-up, and he was completely well with no further concerns. US repeated on day 15 of illness (outpatient setting) showed a complete resolution of the fluid pockets that were seen before.

\section{Discussion and conclusion}

The most common clinical presentation of salmonellosis is acute enteritis, in which the child will present with an abrupt onset of nausea, vomiting, abdominal pain and cramps, located primarily in the periumbilical area and right lower quadrant. This stage is typically followed by mild to severe watery diarrhea and sometimes by diarrheal stool containing blood and mucus. A large proportion of children with acute enteritis are febrile, although younger infants may exhibit a normal or subnormal temperature. Salmonella gastroenteritis can be associated with acute dehydration and complications that result from delayed presentation and inadequate treatment [1].

A total of $1-5 \%$ of children with Salmonella gastroenteritis can develop transient bacteremia. Following bacteremia, salmonellae have the propensity to seed and cause focal supportive infection of many organs. The most common focal infections involve the skeletal system, meninges, intravascular sites, and sites of preexisting abnormalities [1].

Acute pancreatitis complicating Salmonella gastroenteritis is a rare complication among the pediatric population [7]. This complication has been reported in adult patients with typhoid fever and nontyphoid 


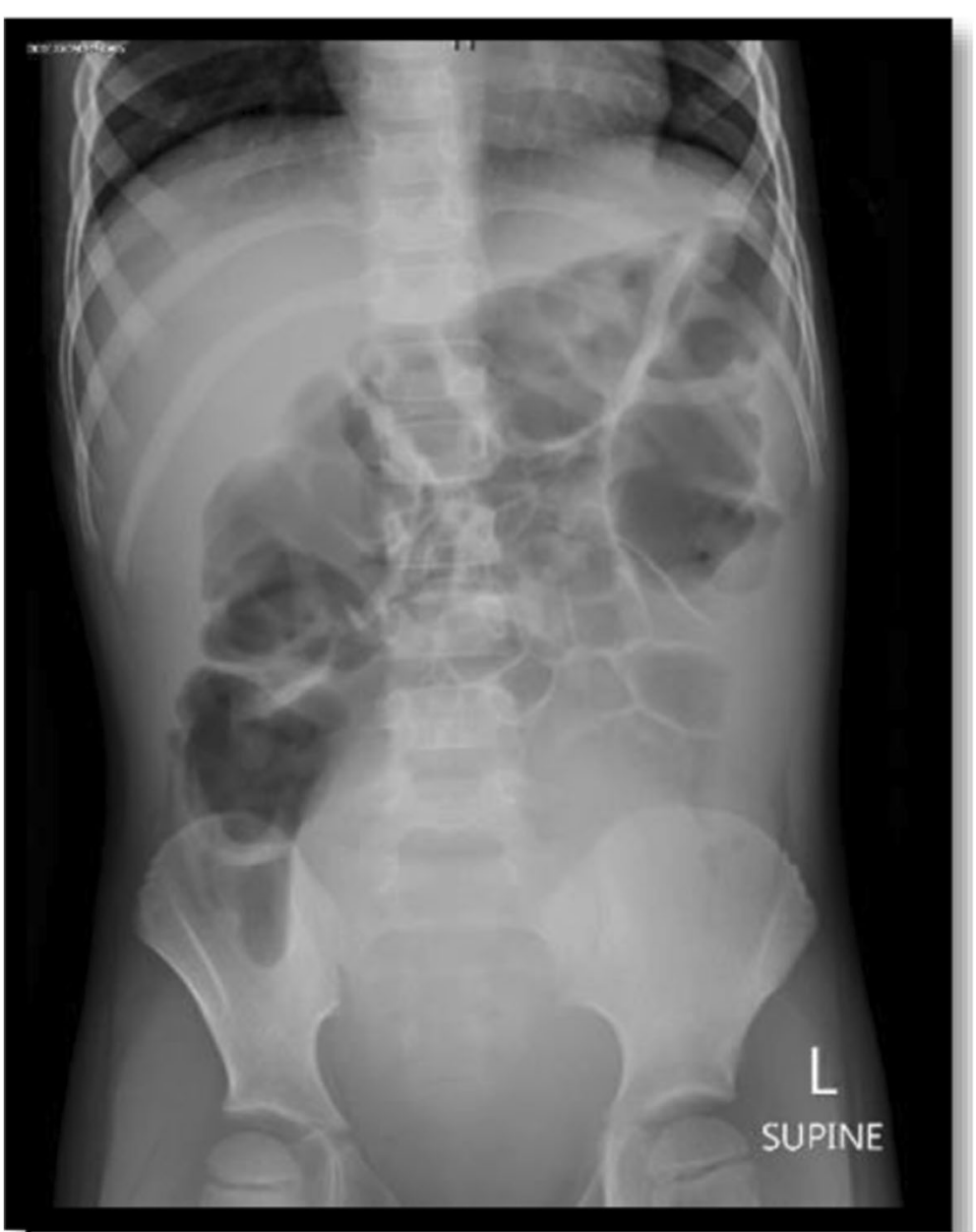

Fig. 2 Abdominal Xray showing gas distension of the transverse colon

Salmonella infection, but there are few reported cases in the pediatric population [7].

Most cases of Salmonella gastroenteritis are associated with biochemical pancreatitis that is characterized by an acute elevation of serum amylase and lipase without clinical correlation. However, there is no agreement that acute pancreatitis could be regarded as a complication of Salmonella infection [9].

Boyd [10] mentioned that necropsy on some patients who died from Salmonella food poisoning showed subtle diffuse acute interstitial pancreatitis. Since these patients died from bacterial or endotoxin shock, pancreatitis

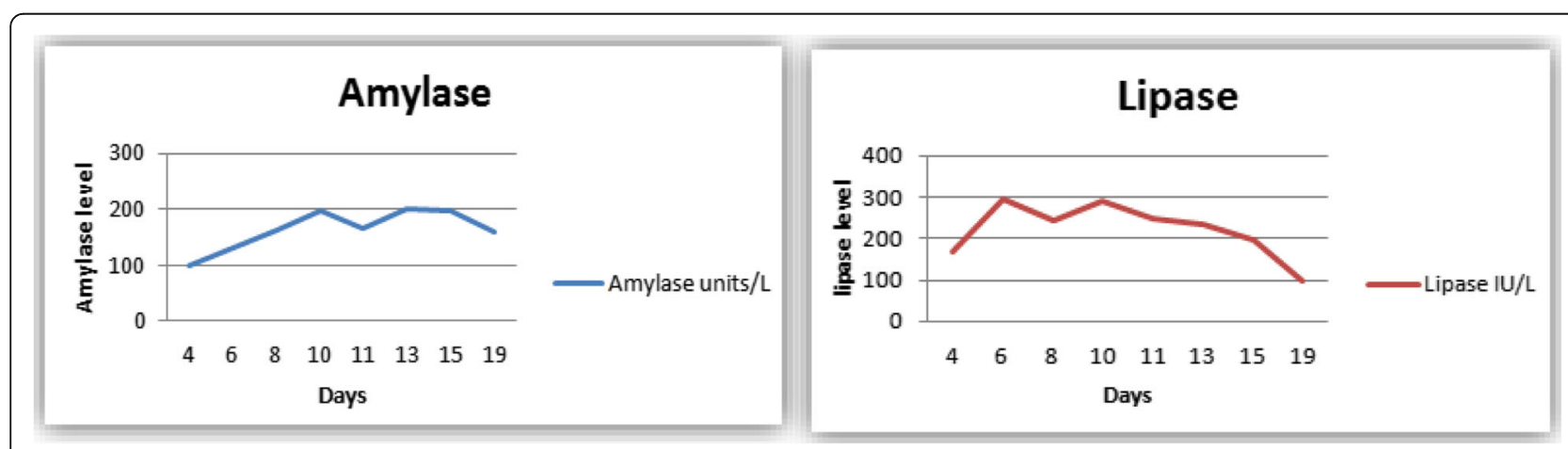

Fig. 3 Trend in the pancreatic enzymes amylase and lipase over the course of the patient's hospital stay 
might be one of the signs of multiorgan failure. Later, two studies were conducted retrospectively on patients with Salmonella enteritis. Renner et al. [11] reported that concomitant pancreatitis was observed in $62 \%$ of patients and that the course of pancreatitis was mild to moderate in most of the patients. Murphy et al. [12] found that none of the 51 patients who presented with Salmonella infection had clinically apparent pancreatitis, and one patient had a mild elevation of serum amylase without clinical correlation. The interpretation of such inconsistent conclusions from both retrospective studies is not clear.

Hermans et al. [13] studied 14 patients with typhoid fever and found that 7 patients had elevated serum amylase and lipase levels on admission, and 4 out of the 14 patients showed clinical signs of pancreatitis. Baert et al. [14] studied 31 patients with Salmonella gastroenteritis and found that $22 \%$ of patients experienced an elevation in serum lipase. In each patient, pancreatitis was mild with minimal changes in the US. On the basis of these studies, we concluded that Salmonella infection can be associated with chemical pancreatitis but not necessarily with clinically evident pancreatitis.

The mechanism of pancreatitis in patients with Salmonella infection is not well understood, although hematogenous or lymphatic spread are the proposed theories. Direct penetration of the pancreas via the migration of salmonellae to the pancreatic duct from the duodenum and biliary tree is another theory, and finally, it is also theorized that toxin-induced or immunemediated pancreatitis can be associated with Salmonella infection [15] [16].

Our patient had multiple reasons for his abdominal pain. Although he tested positive for GAS, the history and physical examination were not supportive of such infection. Therefore, we believe that the positive rapid antigen detection test indicated a carrier state rather than a true infection. We also believe that the pain and the high-grade fever in this patient may have been attributable to intra-abdominal abscesses, as manifested in the US by multiple fluid pockets that responded well to antibiotic therapy. However, this possibility is contradicted by the nature of the pain and its location. Since the pain was mainly located in the epigastric area and aggravated by food intake, the diagnosis of AP rather than another pathology is suggested, but this is not $100 \%$ accurate. The fluid pockets were mainly located in the lower abdomen and therefore should have different pain characteristics.

The patient's clinical response was excellent. Whether the patient's improvement was due to antibiotics or supportive management for AP is unknown. Thus, whether Salmonella can lead to clinically evident pancreatitis remains unclear, and further studies must be done to answer this question. In this case, abdominal CT was the diagnostic imaging method of choice and it is a superior test compared to abdominal US that might have solved the confusion, but unfortunately, it was not done, as the family refused any further imaging.

In conclusion, although AP is a rare complication of Salmonella infection in the pediatric population, general pediatricians should entertain, the possibility of AP when patient presents with severe abdominal pain mimicking the characteristics of the pain associated with AP. Early screening and intervention will lead to better outcomes by decreasing the mortality and morbidity rates associated with Salmonella infection.

\begin{abstract}
Abbreviations
AP: Acute pancreatitis; IV: Intravenous; GAS: Group A streptococcus; CRP: CReactive protein; US: Ultrasound; CT: Computerized tomography; WBC: White blood cells; INSPPIRE: International Study Group of Pediatric Pancreatitis
\end{abstract}

\section{Acknowledgments}

We thank the parents of the patient for allowing us to use the patient's data and to publish this case report.

\section{Availability of data and material}

Not applicable.

\section{Authors' contributions}

SA drafted the manuscript, carried out the literature review, and prepared the illustrations. AA performed the final proofreading of the manuscript. HA helped draft the manuscript. All the above mentioned authors read and approved the final manuscript.

\section{Funding}

This work is not supported by any sponsors. No funding was required in this study.

\section{Declarations}

Ethical approval and consent to participate

This case report was approved by the Ethics Committee of Tawam Hospital. Written consent was obtained from the parents for the standard medical care given to their child as described in this case study.

\section{Consent for publication}

Written informed consent was obtained from the patient's parents for the publication of this case report, images, and all information contained in it.

\section{Competing interests}

The authors declare that they have no conflicts of interest regarding this article's content.

\section{Author details}

${ }^{1}$ Pediatrics Department, General Pediatrics Division, Tawam Hospital, P.O. Box 15258, Al Ain, UAE. ${ }^{2}$ Department of Academic Affairs, Tawam Hospital, Al Ain, United Arab Emirates.

Received: 28 March 2021 Accepted: 19 July 2021

Published online: 17 August 2021

\section{References}

1. Kliegman RM, Nelson WE. Nelson textbook of pediatrics. Philadelphia: Elsevier, PA; 2020. 19103-2899.

2. Morinville VD, Barmada MM, Lowe ME. Increasing incidence of acute pancreatitis at an American pediatric tertiary care center: is greater awareness among physicians responsible? Pancreas. 2010;39(1):5-8. https:// doi.org/10.1097/MPA.0b013e3181baac47. 
3. Nydegger A, Heine RG, Ranuh R, Gegati-Levy R, Crameri J, Oliver MR. Changing the incidence of acute pancreatitis: 10-year experience at the Royal Children's hospital. Melbourne J Gastroenterol Hepatol. 2007;22(8): 1313-6. https://doi.org/10.1111/j.1440-1746.2007.04936.x.

4. Banks PA, Bollen TL, Dervenis C, Gooszen HG, Johnson CD, Sarr MG, et al. Classification of acute pancreatitis - 2012: revision of Atlanta classification and definitions by international consensus. Gut. 2013;62(1):102-11. https:/ doi.org/10.1136/gutjnl-2012-302779.

5. Morinville VD, Husain SZ, Bai H, Barth B, Alhosh R, Durie PR, et al. Definition of pediatric pancreatitis and survey of present clinical practice. J Pediatr Gastroentrol Nutr. 2012;55(3):261-5. https://doi.org/10.1097/MPG.0b013e31 $824 f 1516$.

6. Morinville VD, Lowe ME, Ahuja M, Barth B, Bellin MD, Davis H, et al. Design and implementation of inspire (INternational study Group of Pediatric Pancreatitis: in search for a cure). J Pediatr Gastroenterol Nutr. 2014;59(3): 360-4. https://doi.org/10.1097/MPG.0000000000000417.

7. Pérez-Moreno J, González-Pinto LC, Martínez FG, Castillo BTG, Fernández RR. Pancreatitis aguda como complicación de gastroenteritis por Salmonella, una asociación poco habitual. Anales De Pediatría. 2016;85(5):269-72. Available from: https://www.analesdepediatria.org/es-pancreatitis-agudacomo-complicacion-gastroenteritis-articulo-S1695403316300078. https://doi. org/10.1016/j.anpedi.2016.02.011.

8. Kahl L, Hughes HK. The Harriet Lane Handbook [Internet]. The Harriet Lane Handbook - 22nd Edition. The Johns Hopkins Hospital; 2020 [cited 2021May17]. Available from: https://www.elsevier.com/books/the-harriet-la ne-handbook/kleinman/978-0-323-67407-2.

9. Hamaguchi H, Okabayashi Y, Yoneda R, Ueno H, Yoon S, Sakaue M, Kasuga M A case of acute pancreatitis complicating Salmonella enteritis. In J Gastrointestinal Cancer. 1999;26(3):189-92. Available from: https:/link.springer. com/article/10.1385/JGC:26:3:189, https:/doi.org/10.1385/ijgc:26:3:189.

10. Boyd JF. Salmonella typhimurium, colitis, and pancreatitis. Lancet. 1969; 2(7626):901-2. https://doi.org/10.1016/s0140-6736(69)92352-6.

11. Renner F, Nimeth C, Demmelbauer N. High frequency of concomitant pancreatitis in Salmonella enteritis. Lancet. 1991;338:571.

12. Murphy S, Beeching NJ, Rogerson SJ, Harries AD. Pancreatitis associated with salmonella enteritis. Lancet. 1991;338(8766):571. https://doi.org/10.101 6/0140-6736(91)91134-G.

13. Hermans P, Gerard M, van Laethem Y, De Wit S, Clumeck N. Pancreatic disturbances and typhoid fever. Scand J Infect Dis. 1991;338:571.

14. Baert D, De Man M, Oosterbosch L, Duyck MC, Van der Spek P, Lepoutre L. Infectious gastroenteritis: are they all the same? Acta Clin Belg. 1995;50(5): 269-73. https://doi.org/10.1080/17843286.1995.11718460.

15. Schmid SW, Uhl W, Friess $H$, Malfertheiner $P$, Büchler MW. The role of infection in acute pancreatitis. Gut. 1999:45(2):311-6. 10403749. https://doi. org/10.1136/gut.45.2.311

16. Arendt T. Bile-induced acute pancreatitis in cats. Roles of bile, bacteria, and pancreatic duct pressure. Dig Dis Sci. 1993;38(1):39-44. 8420758. https://doi. org/10.1007/BF01296771

\section{Publisher's Note}

Springer Nature remains neutral with regard to jurisdictional claims in published maps and institutional affiliations.

Ready to submit your research? Choose BMC and benefit from:
- fast, convenient online submission
- thorough peer review by experienced researchers in your field
- rapid publication on acceptance
- support for research data, including large and complex data types
- gold Open Access which fosters wider collaboration and increased citations
- maximum visibility for your research: over 100M website views per year
At BMC, research is always in progress.
Learn more biomedcentral.com/submissions

